\title{
PREVISÃO DA VOLATLLIDADE NO MERCADO INTERBANCÁRIO DE CÂMBIO
}

RESUMO

O artigo apresenta um estudo comparativo da capacidade preditiva dos modelos EW MA, GARCH $(1,1)$, $\operatorname{EGARCH}(1,1)$ eTARCH $(1,1)$, quand o utilizados para prever a volatilidade das taxas de câmbio praticadas no mercado interbancário brasileiro. A amostra é composta pelas cotações diárias de fechamento da taxa de câmbio real/dólar estadunidense observadas no período de 20 de agosto de 2001 a 30 de setembro de 2003. Os resultados demonstraram que o modelo TARCH $(1,1)$ apresentou o mel hor desempenho preditivo para o período, acompanhado de perto pelo modelo $\operatorname{EGARCH~}(1,1)$, seguindo-se o modelo $\mathrm{GARCH}$ $(1,1)$ e, por último, o modelo EW MA. Constatou-se também que todos os modelos revelaram uma propensão a superestimar a volatilidade futura, e que a Clearing de Câmbio da BM \& $F$ atua de forma excessivamente conservadora e subjetiva na definição dos índices de variação da taxa de câmbio contratualmente garantidos e, conseqüentemente, na exigência de garantias.

\section{Clayton Peixoto Goulart \\ UFMG-CEPEAD}

\section{Hudson Fernandes Amaral \\ UFMG-CEPEAD}

\section{Luiz Alberto Bertucci \\ UFMG-CEPEAD}

\section{Aureliano Angel Bressan}

UFMG-CEPEAD

\begin{abstract}
This paper presents a comparative study of the predictive capacity of the models EW M A, GARCH $(1,1)$ EGARCH $(1,1)$ and TARCH $(1,1)$ when applied to forecast the volatility of the exchange rates in the Brazilian inter-bank market. The sample consists of the daily closing quotations of the exchange rate real/US dollar obtained in the period from August 20, 2001 to September 30, 2003. The results showed that the TARCH $(1,1)$ model, provided the most accurate forecast performance for this period, followed closely by the EGARCH $(1,1)$ model, then the $\operatorname{GARCH}(1,1)$ model, and finally the EW M A model. There was also evidence that all the models revealed a tendency to overestimate the future volatility. It was confirmed as well that the Brazilian Exchange Clearinghouse operates in an extremely traditional and subjective way concerning the definition of the exchange rate variation indexes guaranteed under contract and, consequently, in collateral requirements.
\end{abstract}

PALAVRAS-CHAVE Volatilidade, câmbio, risco, modelos econométricos.

KEYWORDS Volatility, exchange, risk, econometrics models. 


\section{CLAYTON PEIXOTO GOULART •HUDSON FERNANDES AMARAL •LUIZ ALBERTO BERTUCCI •AURELIANO ANGEL BRESSAN}

\section{INTRODUÇÃO}

Desde o trabalho inicial de Markowitz (1952), a volatilidade é uma variável presente em grande parte da moderna teoria de finanças e dos processos de tomada de decisão financeira. N esse sentido, Bollerslev, Chou e Kroner (1992, p. 46) afirmam que a "volatilidade é uma variável-chave que permeia a maioria dos instrumentos financeiros e que exerce um papel central em diversas áreas de finanças". Entretanto, passados mais de 50 anos de pesquisas e discussões acadêmicas, observa-se que ainda não há um consenso sobre o modelo mais adequado para o cálculo da volatilidade, gerando ainda calorosas discussões e abrindo um amplo campo de pesquisas.

Durante muitos anos a proposição dominante nas publicações científicas financeiras e nas aplicações de mercado era baseada na pressuposição de que se poderia considerar a volatilidade dos retornos dos ativos financeiros como um fator constante no tempo. Embora Mandelbrot (1963) e Fama (1965) já tivessem alertado para as mudanças na volatilidade dos ativos ao longo do tempo, destaca-se a ênfase dada por M erton (1980, p 354) no que se refere à necessidade do "desenvolvimento de modelos mais precisos de estimação de variâncias que levassem em conta os erros de estimativas passadas".

Como preconizado por Merton (1980), Engle (1982) propôs uma nova classe de processos estocásticos denominada Autoregressive Conditional $H$ eteroskedasticity [heteroscedasticidade condicional auto-regressiva] $(\mathrm{ARCH})$, na qual a variância de uma série temporal modifica-se, com o passar do tempo, de forma condicional aos erros de previsão observados no passado. Posteriormente, Bollerslev (1986) generalizou o tratamento da variância condicional por meio do modelo intitulado G eneralized Autoregressive Conditional Heteroskedasticity [heteroscedasticidade condicional auto-regressiva generalizada] (GARCH), no qual a variância condicional em um determinado tempo t depende não somente dos erros de previsão observados no passado, como também das variâncias condicionadas observadas no passado (Alexander 2002; Brooks, 2002).

Durante os anos que se seguiram, diversas variantes dos modelos originais ARCH e GARCH foram desenvolvidas no sentido de melhor representar o comportamento dos diversos ativos nos mercados financeiros, por vezes apresentando maior complexidade matemática e, conseqü entemente, de implementação; por vezes adotando simplificações que, por pouco, não descaracterizam os princípios básicos dos modelos originais. Dentre os modelos simplificados, destacase 0 adotado pelo RiskMetrics ${ }^{\mathrm{TM}}$, denominado Exponentially Weighted Moving Averages [modelo de médias móveis ponderadas exponencialmente] (EWMA), que pode ser interpretado como um caso especial do modelo Integrated GARCH (I-GARCH), e que obteve ampla aceitação pelo mercado financeiro (Alexander, 1998).

No campo acadêmico, foram e são efetuados diversos estudos empíricos testan do a capacidade preditiva dos modelos da família ARCH, principalmente nos mercados de câmbio e de ações, originando um grande número de artigos, teses e dissertações sobre 0 assunto. No âmbito comercial, embora no início dos anos 1990 fosse possível considerar que os model os ARCH - como ferramentas de decisão - estivessem em um estágio ainda experimental, atualmente muitas instituições já detêm a competência necessária para utilizáIos (Gouriéroux, 1997). No Brasil, infelizmente, tanto no âmbito acadêmico como no comercial, ainda não se observa o mesmo volume de publicações, pesquisas e aplicativos que se constata nos mercad os financei ros dos países desenvolvidos, principalmente no que se refere ao mercado de câmbio. Vários motivos podem ser levantados para esse fato, sendo o mais relevante as diversas mudanças de regime cambial ocorridas nos últimos 30 anos, inseridas ou não no contexto de um plano de estabilização financeira.

Entretanto, recentemente diversos fatores vieram a contribuir para a criação de um ambiente propício à consecução de novos estudos sobre o tema no mercado cambial brasileiro. Podem ser destacados: a) adoção da política de câmbio livre, a partir de janeiro de 1999, com a redução da participação do Estado - em especial do Banco Central do Brasil (Bacen) - na definição do patamar da taxa de câmbio corrente; b) a implementação do novo Sistema de Pagamentos Brasileiro (SPB), a partir de 22 de abril de 2002, com a formalização e institucionalização das Câmaras de Registro, Compensação e Liquidação - Clearings -, em particular da Clearing de Câmbio da Bolsa de M ercadorias e Futuros (BM\& $\&$ ); e, c) a necessidade de incremento do comércio exterior, visando a obtenção de superávits comerciais crescentes.

Dessa forma, este artigo apresenta um estudo comparativo da capacidade preditiva de modelos da família ARCH (GARCH, EGARCH e TARCH) em relação ao modelo EWMA - adotado pelo RiskM etrics ${ }^{T M}$ e pela 
Clearing de Câmbio da BM \& F - , no sentido de contribuir não apenas para preencher parte da lacuna observada nos estudos relativos aos modelos de predição de volatilidade no mercado de câmbio interbancário brasileiro, como também para apresentar um estudo científico da capacidade preditiva dos modelos aplicados a processos de gerenciamento de riscos e controle de garantias no referido mercado. Ademais, 0 estudo pode servir como referência para discussões futuras, por parte da autoridade monetária, da Clearing de $C$ âmbio da BM\& $F$ e dos operadores de mercado, sobre a pertinência da utilização de modelos econométricos mais elaborados no procedimento de definição do índice de variação da taxa de câmbio contratualmente garantido pela câmara.

\section{REFERENCIAL TEÓRICO}

Ao contrário dos preços, a volatilidade não é diretamente observável no mercado, podendo apenas ser estimada no contexto de um modelo. Dessa forma, é plenamente possível a obtenção de diferentes valores de volatilidade utilizando-se um mesmo conjunto de dados, bastando utilizar modelos distintos, que são, em sua grande maioria, teoricamente bem fundamentados (Alexander, 2002). Conforme mostram Poon e Granger (2003), em pesquisa realizada em 93 artigos e working papers publicados no período de 1976 a 2002, a diversidade de resultados ainda não permite que se firme um consenso sobre a capacidade preditiva dos diversos modelos de predição de volatilidade, configurando-se um amplo campo para pesquisas e debates. N esse sentido, e no caso específico desta pesquisa, optou-se por comparar a capacidade preditiva dos model os EWMA, GARCH $(1,1), \operatorname{EGARCH}(1,1)$ e TARCH $(1,1)$, sobre os quais será efetuada uma breve discussão a seguir.

Segundo Brooks (2002, p. 442), "o modelo de média móvel com ponderação exponencial (EWMA) é, essencialmente, uma simples extensão do modelo de volatilidade histórica ponderada, no qual as observações mais recentes têm um impacto maior na previsão da volatilidade que os dados mais antigos". De outra sorte, Alexander (1998) postula que o modelo EWMA pode ser entendido como uma simplificação do modelo IGARCH, no qual considera-se a volatilidade de longo prazo igual a zero. Formalmente, o modelo de médias móveis com ponderação exponencial, para $n$ períodos de uma série temporal constituída dos retor- nos de um ativo, pode ser definido como (Alexander, 2002):

$$
\sigma_{t}^{2}=(1-\lambda) \cdot \sum_{i=1}^{n} \lambda^{i-1} \cdot\left(r_{t-i}-\bar{r}\right)^{2} \quad \text { Equação } 1
$$

onde:

$\bar{r}$ é o retorno médio;

$r_{t-i}$ é o retorno da série com t-i defasagens;

$n$ é o número de observações utilizadas;

$\lambda$ é 0 fator de decaimento exponencial, tal que $0<$ $\lambda<1$; e

$\sigma_{t}^{2}$ é a variância prevista para o tempo t.

O modelo EWMA recebeu especial impulso junto ao mercado financeiro a partir de 1994, com o lançamento do software de administração de riscos RiskM etrics ${ }^{\text {TM }}$ pelo J. P. Morgan. A grande aceitação desse software e a divulgação livre do respectivo documento técnico (RiskMetrics: Technical Document, Morgan Guaranty Trust Company \& Reuters Ltd., 1996) rapidamente tornaram a metodologia um padrão de mercado.

Entretanto, é importante observar que o referido documento técnico tece algumas considerações e estabelece premissas para a utilização do modelo no âmbito do software RiskM etrics ${ }^{\mathrm{TM}}$, dentre as quais se destacam: a) os retornos das séries financei ras são calculados de forma contínua, tomando-se o logaritmo da relação entre os preços observados nos períodos t e $\mathrm{t}-1$, considerando o comportamento log-normal dos preços; b) o retorno médio é definido como sendo nulo, para qualquer série financeira e em qualquer intervalo de tempo utilizado; $c$ ) o valor do fator de decai mento $(\lambda)$, quando se utilizam retornos diários, obedece a relação predeterminada, definindo-se um total de 149 observações $(n)$ e $\lambda=0,94$, para qualquer mercado ou ativo analisado; e, d) a volatilidade para múltiplos dias não pode ser estimada diretamente por meio do modelo EWMA (tipicamente um modelo do tipo "um passo à frente"), assumindo-se a regra da "raiz quadrada do tempo" para se calcular a volatilidade em períodos maiores.

Em uma outra perspectiva, encontram-se os modelos da classe ARCH. A proposição original, elaborada por Engle (1982), mereceu extensos debates e diversos aperfeiçoamentos ao longo dos anos. A primeira, e mais significativa, foi introduzida por Bollerslev (1986) , ao propor que a volatilidade condicionada fosse função não apenas dos quadrados dos erros passa$\operatorname{dos}\left(\varepsilon_{\mathrm{t}-\mathrm{i}}^{2}\right)$, como também dos seus próprios valores 
passados $\left(\sigma_{\mathrm{t}-\mathrm{j}}^{2}\right)$, passando os modelos assim construídos a ser denominados Generalized ARCH ( $G A R C H)$. Em termos matemáticos, um modelo $\mathrm{GARCH}(p, q)$ pode ser expresso como:

$$
\begin{array}{ll}
\sigma_{t}^{2}=\omega+\sum_{i=1}^{q} \alpha_{i} \cdot \varepsilon_{t-i}^{2}+\sum_{j=1}^{p} \beta_{j} \cdot \sigma_{t-j}^{2}+v_{t} \quad \text { Equação } 2
\end{array}
$$

onde:

$\sigma_{t}^{2}$ é a é variância condicionada em t;

$\omega$ é a constante;

$\varepsilon_{\mathrm{t}-\mathrm{i}}$ é o erro observado no tempo t-i, em que i denota a defasagem;

$\alpha_{i}$ é a constante multiplicadora do termo de defasagem i;

$\beta_{1}$ é a constante multiplicadora do termo de defasagem $\mathrm{j}$;

$\sigma_{\mathrm{t}-\mathrm{j}}^{2}$ é a variância condicionada observada em t-j; e, $v_{\mathrm{t}}$ é um ruído branco $[\mathrm{N} \sim(0,1)]$.

Saliente-se que, para se garantir que a variância condicionada não seja negativa, e também a estacionariedade do processo, as seguintes restrições devem ser impostas à Equação 1 : $\omega>0 ; \alpha_{i} \geq 0$, para $i=1, \ldots, p$; $\beta_{\mathrm{j}} \geq 0$, para $\mathrm{j}=1, \ldots, \mathrm{q}$; e $\sum_{i=1}^{p} \alpha_{i}+\sum_{j=1}^{q} \beta_{j}<1$

Outro ponto a se salientar é que, apesar de o modeIo GARCH $(p, q)$ captar corretamente diversas características observadas nas séries históricas de finanças, tais como a leptocurtose e o agrupamento de volatilidades, não capta o efeito de al avancagem, uma vez que a variância condicional é função apenas da magnitude das inovações e não dos seus sinais (Brooks, 2002). Assim, surgiram algumas extensões com a finalidade de modelar o problema da assimetria, tais como os modelos EGARCH eTARCH.

0 modelo EGARCH (Exponential GARCH) foi proposto por N elson (1991), apresentando duas vantagens em relação ao model o GARCH : a incorporação dos efeitos assimétricos de mercado aos modelos auto-regressivos de volatilidade condicionada, e a não imposição artificial de restrições aos parâmetros da equação, dada a sua formulação em termos logarítmicos. Por outro lado, o referido modelo necessita de adaptações para sua implementação computacional e, por vezes, apresenta um al to grau de persistência após choques significativos de volatilidade. Segundo Brooks (2002), há vários modos de se expressar a equação da variância condicional, dentre os quais:

$$
\ln \left(\sigma_{t}^{2}\right)=\omega+\beta \cdot \ln \left(\sigma_{t-1}^{2}\right)+\gamma \cdot \frac{\varepsilon_{t-1}}{\sigma_{t-1}}+\alpha\left[\frac{\left|\varepsilon_{t-1}\right|}{\sigma_{t-1}}-\sqrt{\frac{2}{\pi}}\right]+v_{t}
$$

Equação 3

onde:

$\sigma_{t}^{2}$ é a variância condicionada em $t$;

$\omega$ é a constante;

$\varepsilon_{\mathrm{t}-1}$ é o erro observado no tempo t- 1 ;

$\alpha, \beta, \gamma$ são coeficientes da equação;

$\sigma_{\mathrm{t}-1}$ é o desvio padrão observado em t-1; e

$v_{t}$ é um ruído branco $[N \sim(0,1)]$.

Um modelo mais simples e intuitivo para a captação do comportamento assimétrico das séries financeiras foi apresentado por Glosten, Jagannathan e Runkle (1993), sendo denominado modelo GJR ou TARCH (Threshold ARCH). Nesse novo modelo, é acrescentado um termo à equação-padrão $\mathrm{GARCH}$, cuja função é o reconhecimento dos efeitos assimétricos à volatilidade condicional, ou seja:

$$
\sigma_{t}^{2}=\omega+\sum_{i=1}^{q} \alpha_{i} \cdot \varepsilon_{t-i}^{2}+\gamma \cdot \varepsilon_{t-i}^{2} \cdot d_{t-1}+\sum_{j=1}^{p} \beta_{i} \cdot \sigma_{t-j}^{2}+v_{t}
$$

Equação 4

onde:

$\sigma^{2}$ t é a variância condicionada em t;

$\omega$ é a constante;

$\varepsilon_{\mathrm{t}-\mathrm{i}}$ é o erro observado no tempo t-i, onde i denota a defasagem;

$\alpha_{i}$ é a constante multiplicadora do termo de defasagem i;

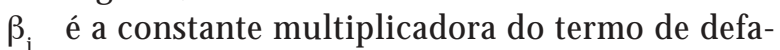
sagem $\mathrm{j}$;

$\sigma_{t-j}^{2}$ é a variância condicionada observada em t-j;

$\gamma$ é o coeficiente do termo de assimetria;

$\mathrm{d}_{\mathrm{t}-1}$ é a variável dummy que assume 0 valor igual a 1

se $\varepsilon_{\mathrm{t}-1}<0$ (más notícias), e valor igual a 0 se $\varepsilon_{\mathrm{t}-1}>0$ (boas notícias); e

$v_{\mathrm{t}}$ é um ruído branco $[\mathrm{N} \sim(0,1)]$.

Destacando que, como no modelo GARCH, as condições para não negatividade e estacionariedade são: $\omega \geq 0 ; \alpha_{i} \geq 0$, para $i=1, \ldots, q ; \beta_{i} \geq 0$, para $j=1, \ldots, p ;$ e $\Sigma \alpha_{i}+\gamma \geq 0$ (Brooks, 2002).

Evidentemente, a importância dos modelos acima citados está diretamente relacionada ao uso da volatilidade prevista nos processos de tomada de decisão financeira, precificação de ativos e nas metodologias de gerenciamento de risco. No caso específico da Clearing 
de Câmbio da BM \& F, a utilização da volatilidade prevista está descrita no Anexo I do seu Manual de Gerenciamento de Risco, qual seja: os índices de variação da taxa de câmbio contratualmente garantidos - base para a exigência de garantias a serem depositadas pelos participantes - são determinados pela conjunção de duas análises. A primeira, a estimação da volatilidade, por meio de modelos econométricos (avaliação objetiva); e a segunda, a avaliação da conjuntura macroeconômica pelo Comitê da Câmara (avaliação subjetiva). A parcela estatística do índice (avaliação objetiva) segue a abordagem paramétrica sugerida por Jorion (1998) para a determinação do "valor em risco" com um nível de confiança de $99 \%$. Assim, para operações negociadas pelo prazo de um dia, o desvio padrão calculado pelo modelo EW M A é multiplicado por 2,33; já para as operações negociadas pelo prazo de dois dias, o desvio padrão é multiplicado por 2,33. $\sqrt{2}$. Ressaltando-se que a decisão final do Comitê da Clearing baseia-se na análise econômica dos fatos ( $B M \& F, 2002$, p. 83).

Observa-se, portanto, que duas questões estão envolvidas nesta pesquisa: a comparação da capacidade preditiva dos modelos anteriormente citados e os possíveis reflexos que uma substituição do modelo EW MA poderia acarretar na definição do índice de taxa de câmbio contratualmente garantido pela Clearing. A próxima seção discorrerá sobre a metodologia empregada para se avaliar essas questões.

\section{PROCEDIMENTOS METODOLÓGICOS}

N este estudo foram utilizadas duas bases de dados. A primeira refere-se às cotações diárias de fechamento da taxa de câmbio real/dólar norte-americano (R\$/US\$) observadas no período de 20 de agosto de 2001 a 30 de setembro de 2003, num total de 536 observações. Os dados foram fornecidos pela Clearing de Câmbio da $B M \& F$ e são os mesmos por el a utilizados nas rotinas internas de cálculo de volatilidade. É importante ressaltar que a utilização de dados no período de 20 de agosto de 2001 a 19 de abril de 2002 foi devida a uma necessidade prática. Conforme observado anteriormente, a Clearing adotou o model o EW M A para o cálculo, qual seja, a janela móvel com 149 observações e fator de decaimento (I) de 0,94. Assim, para viabilizar 0 início das atividades da Clearing em 22 de abril de 2002, a direção da Câmara decidiu utilizar as taxas de câmbio do período de 20/8/2001 a 19/3/2002 (que perfazem um total de 149 observações) como valores iniciais do modelo. Já o intervalo compreendido entre 20 de março de 2002 e 19 de abril de 2002 foi utilizado para o acompanhamento do comportamento da volatilidade no período imediatamente anterior ao início das atividades da Câmara. A escolha da data final para a amostra - 30 de setembro de 2003 - foi arbitrada pelos pesquisadores, não tendo, portanto, nenhum significado especial.

A segunda base de dados refere-se aos índices diários de variação da taxa de câmbio (percentual garantido), estipulados no período de 22 de abril de 2002 a 30 de setembro de 2003, para operações a serem liquidadas em $D+1$ e $D+2$. Também nesse caso, as informações foram disponibilizadas pela Câmara. Para efeito deste estudo, assume-se que as diferenças entre os val ores calculados e os valores estipulados são devidas à parcela subjetiva referente à avaliação macroeconômica.

Com base na premissa de log-normalidade dos preços dos ativos, a série de taxas de câmbio (R\$/US\$) foi transformada por intermédio da equação $r_{t}=\ln P_{t}-\ln P_{t-11^{\prime}}$ resultando em uma série de retornos de taxas de câmbio (um total de 535 observações). Dessa forma, a série de retornos substituiu a série original de cotações de taxas de câmbio como dados de entrada para os testes estatísticos e para os modelos de predição de volatilidade.

O primeiro passo da investigação empírica foi efetuado por meio de uma análise estatística descritiva da série de retornos da taxa de câmbio. Com o intuito de analisar possíveis influências de fatores externos no comportamento dos retornos da taxa de câmbio, os testes foram realizados na série completa (de 21 de agosto de 2001 a 30 de setembro de 2003, perfazendo 535 observações) e em três subperíodos, a saber: a) de 21 de agosto de 2001 a 19 de abril de 2002, perfazendo 170 observações, cuja motivação foi verificar o comportamento da série no período de antecede o início de operação da Câmara e do novo SPB; b) de 22 de abril de 2002 a 30 de dezembro de 2002, perfazendo 177 observações, buscando observar o comportamento da série no período pré-eleitoral brasileiro; e c) de 2 de janeiro de 2003 a 30 de setembro 2003, perfazendo 188 observações, no intuito de observar o comportamento da série em um período de estabilização de um novo governo, marcado por uma política fiscal e monetária restritiva.

O segundo passo visou constatar a presença de heteroscedasticidade condicional auto-regressiva na 
série de retornos, pois tal característica é condição fundamental para justificar a aplicação de modelos da família ARCH. Sobre os mesmos períodos acima especificados, foi aplicado o teste ARCH-LM (ARCH Lagrange Multipliers), conforme sugerido por Engle (1982). Os testes foram realizados com o auxílio do software Eviews ${ }^{\mathrm{TM}}$ 4.0.1

O modelo EWMA foi implementado na sua forma não-recursiva, conforme apresentada na Equação 1, com $n=149$ e $\lambda=0,94$. Os cálculos relativos a esse model o foram efetuados com o uso da planilha el etrônica M icrosoft ${ }^{\oplus}$ Excel 2000 , por meio de rotina desenvolvida pelos autores deste artigo.

Antes de descrever os modelos da família ARCH, é importante ressaltar que sua utilização exigiu a definição em conjunto de uma equação para a média condicional, uma vez que os erros apurados na equação da média são os insumos necessários à operacionalização dos cálculos da volatilidade condicionada. Alexander (1998) postula que, quanto mais parcimoniosa for a definição da equação da média condicional, melhor será possível avaliar o desempenho do model o. Dessa forma, neste estudo, foi ad otada a equação $r_{t}=c+\varepsilon_{t}$ (regressão do retorno apenas sobre uma constante) como padrão para o cál culo da média condicional em todas as oportunidades em que se fez necessário.

Definida a equação da média condicional, os erros gerados serviram de insumo para as seguintes parametrizações dos modelos de volatilidade condicionada da família ARCH:

$\operatorname{GARCH}(1,1)$ :

$\sigma_{t}^{2}=\omega+\beta \cdot \sigma_{t-1}^{2}+\alpha \cdot \varepsilon_{t-1}^{2}$

Equação 5

$\operatorname{EGARCH}(1,1)$ :

$\ln \sigma_{t}^{2}=\omega+\beta \cdot \ln \sigma_{t-1}^{2}+\alpha \cdot\left|\frac{\varepsilon_{t-1}}{\sigma_{t-1}}\right|+\gamma \cdot \frac{\varepsilon_{t-1}}{\sigma_{t-1}}$

Equação 6

$\operatorname{TARCH}(1,1)$ :

$$
\sigma_{t}^{2}=\omega+\beta \cdot \sigma_{t-1}^{2}+\alpha \cdot \varepsilon_{t-1}^{2}+\gamma \cdot \varepsilon_{t-1}^{2} \cdot d_{t-1}
$$

Equação 7

Por fim, todas as estimações dos parâmetros e cálculos dos model os de volatilidade condicionada foram efetuadas com o auxílio do software econométrico Eviews $^{T M}$ (versão 4.0), ressaltando-se que: a) os modelos foram estimados pelo método de log-máxima verossimilhança, sob a assunção de que os resíduos condicionais são normalmente distribuídos; b) para minimizar as possibilidades de erros oriundos da detecção de máximos locais em vez de máximos globais da função de log-máxima verossimilhança, ajustou-se o critério de convergência do processo iterativo para $10^{-5}$ e o número máximo de iterações para 8.000; c) 0 algoritmo de otimização escolhido foi $\mathrm{BHHH}$ (Berndt-Hall-Hall-Hausman), com o critério selecionado para privilegiar a precisão e não a velocidade; $d$ ) foi utilizada a opção de backcasting, sugerida pelo Manual do Usuário de Eviews ${ }^{\mathrm{TM}}$; e, e) as previsões foram efetuadas com a rotina forecast, ajustando-se para 0 método dinâmico.

Como a volatilidade não pode ser diretamente observada, faz-se necessária a definição de um processo para se determinar esse parâmetro ou, em outras palavras, para se calcular o que será considerado como a "volatilidade real". Para este trabalho, como o foco de observação será a previsão da volatilidade diária para um horizonte máximo de dois dias úteis, optou-se pelo procedimento utilizado por Pagan e Schwert (1990), Day e Lewis (1992) e Bertucci (1999), que consiste em calcular a volatilidade instantânea por intermédio da seguinte equação:

$$
\begin{array}{ll}
\sigma_{i t}^{2}=\left(r_{t}-\bar{r}\right)^{2} & \text { Equação } 8
\end{array}
$$

onde:

$\sigma^{2}$ it é a volatilidade instantânea para o dia t;

$r_{t}$ é o retorno observado no dia t; e

$\bar{r}$ é o retorno médio observado em cada período das subamostras, consideradas aqui como janelas de 149 observações.

No que tange à capacidade preditiva dos modelos de volatilidade, este estudo empírico restringiu-se a comparações de desempenho "fora da amostra", com ênfase nas previsões para $D+1$ e $D+2$, seguindo 0 atual contexto de negociação real izado no âmbito da Clearing de Câmbio da BM \& F. Os cál culos com o modelo EW M A foram realizados sempre com a utilização de uma janela móvel de 149 observações. Para os modelos da família $\mathrm{ARCH}$, foram empregados dois procedimentos: a utilização de uma janela móvel de 149 observações, visando comparar a capacidade preditiva em condições iguais às fixadas para o modelo EW MA, e a utilização de todas as observações disponíveis até a data imediatamente anterior ao processo de cálculo, buscando-se obter todo o potencial dos model os auto-regressivos de heteroscedasticidade condicional. 
A operacionalização dos cálculos de predição de volatilidade, para o caso em que se utilizou uma janela móvel para todos os modelos, seguiu os seguintes passos: a) o período de 21 de agosto de 2001 a 20 de março de 2002, correspondendo aos primeiros 149 retornos da série, foi utilizado para o cálculo inicial dos modelos; b) como o modelo EW M A não necessita de estimação de parâmetros, as 149 observações iniciais foram diretamente utilizadas para se calcular a previsão para $D+1$ ( 21 de março de 2002). Entretanto, como o referido modelo possibilita apenas a previsão do tipo "um passo a frente", seguindo o procedimento adotado pela Câmara, o valor da volatilidade atribuído para $D+2$ (22 de março de 2002) foi idêntico ao calculado para $\left.\mathrm{D}+1\left(\sigma_{\mathrm{D}+2}^{2}=\sigma_{\mathrm{D}+1}^{2}\right) ; \mathrm{C}\right)$ para os modelos da família $A R C H$, a estimação dos parâmetros foi efetuada com os dados da subamostra, gerando-se, a partir daí, as equações que foram utilizadas na predição da volatilidade. Como os modelos dessa família permitem a projeção para períodos superiores a um dia, foi utilizada a rotina forecast do Eviews ${ }^{\mathrm{TM}}$ nas previsões para $D+1$ e $D+2$; d) na segunda iteração, deslocou-se a amostra em um dia útil, retirando-se a observação mais antiga e acrescentando-se uma nova, estabelecendo-se um novo conjunto com 149 observações. Com base nessa "nova amostra", foram refeitos os passos descritos nos itens b) e c); e) esse processo iterativo de retirada da observação mais antiga e inclusão de uma nova repetiu-se até 26 de setembro de 2003, dois dias úteis antes do final da amostra. 0 resultado final desse procedimento foi uma matriz de oito colunas (previsões para $D+1$ e $D+2$ realizadas por cada um dos modelos) e 385 linhas (número total de iterações).

Já os cálculos de predição de volatilidade utilizando-se todas as informações anteriormente disponíveis, efetuados apenas com os model os $A R C H$, seguiram um procedimento similar ao anteriormente descrito. A diferença reside no fato de que, a cada iteração, uma observação era acrescentada à subamostra, não sendo retirada nenhuma. 0 resultado final desse procedimento foi uma matriz de seis colunas (previsões para $D+1$ e $D+2$ realizadas por cada um dos modelos da família $A R C H$ ) e 385 linhas (número total de iterações).

Dos dois procedimentos descritos anteriormente, realizados por meio de rotina desenvolvida pelos autores deste artigo no software Eviews ${ }^{T M}$, obteve-se uma matriz de previsões de volatilidade de 14 colunas e 385 linhas, contendo os dados necessários para se avaliar o desempenho preditivo dos modelos seleciona- dos. Passou-se, então, para o cálculo das medidas de avaliação de desempenho preditivo.

Conforme descrito anteriormente, adotou-se a "volatilidade instantânea" (Equação 8) como medida representativa ( proxy) da volatilidade diária. Assim, para o período compreendido entre 21 de março de 2002 e 30 de setembro de 2003, foram calculadas as volatilidades diárias por meio do seguinte procedimento: a) definiu-se uma subamostra composta pelos 149 retornos compreendidos entre os dias 22 de agosto de 2001 e 21 de março de 2002; b) calculou-se a média aritmética da subamostra, decrementando-a do retorno observado no último dia. Elevou-se ao quadrado o resultado dessa operação para se obter a volatilidade instantânea para o último dia da amostra; c) deslocou-se a subamostra retirando-se a observação mais antiga e acrescentando-se uma nova, mantendo-se um total de 149 observações; d) repetiram-se os itens b) e c) até 0 dia 30 de setembro de 2003, obtendo-se um vetor composto pelas 386 volatilidades instantâneas do período.

0 terceiro passo consistiu em estabelecer as medidas de avaliação de desempenho da capacidade preditiva dos modelos. Com base na matriz de previsões de volatilidade e do vetor de volatilidades instantâneas, foi possível efetuar a avaliação acerca do desempenho dos model os na predição por intermédio das seguintes medidas:

a) Erro absoluto médio:

$E A M_{D+1}=\frac{\sum_{n=1}^{385}\left|\sigma_{i n_{D+1}}^{2}-\sigma_{p n_{D+1}}^{2}\right|}{385} \quad E A M_{D+2}=\frac{\sum_{n=1}^{385}\left|\sigma_{i n_{D+2}}^{2}-\sigma_{p n_{D+2}}^{2}\right|}{385}$

b) Raiz do erro quadrático médio

$$
\operatorname{REQM}_{D+1}=\left[\frac{\sum_{n=1}^{385}\left(\sigma_{i n_{D+1}}^{2}-\sigma_{p n_{D+1}}^{2}\right)^{2}}{385}\right]^{\frac{1}{2}} \quad R E Q M_{D+2}=\left[\frac{\sum_{n=1}^{385}\left(\sigma_{i n_{D+2}}^{2}-\sigma_{p n_{D+2}}^{2}\right)^{2}}{385}\right]^{\frac{1}{2}}
$$

c) Estatística Theil-U

$$
\text { Theil }-U_{D+1}=\frac{\sum_{n=1}^{385}\left(\sigma_{p n_{D+1}}^{2}-\sigma_{i n_{D+1}}^{2}\right)^{2}}{\sum_{n=1}^{385}\left(\sigma_{R W n_{D+1}}^{2}-\sigma_{i n_{D+1}}^{2}\right)^{2}} \quad \text { Theil }-U_{D+2}=\frac{\sum_{n=1}^{385}\left(\sigma_{p n_{D+2}}^{2}-\sigma_{i n_{D+2}}^{2}\right)^{2}}{\sum_{n=1}^{385}\left(\sigma_{R W n_{D+2}}^{2}-\sigma_{i n_{D+2}}^{2}\right)^{2}}
$$

onde:

$E A M_{D+n}$ é o erro absoluto médio nas previsões para $D+n$;

REQM $_{D+n}$ é a raiz do erro quadrático médio nas previsões para $D+n$; 
Theil- $U_{D+n}$ é a estatística Theil-U referente às previsões para $D+n$;

$\sigma^{2}{ }^{i n+k}$ é a volatilidade instantânea para a $D+k$ $(k=[1,2])$ em relação à observação $n$;

$\sigma^{2}{ }^{p n_{D+k}}$ é a volatilidade prevista para a $D+k$ $(k=[1,2])$ em relação à observação $n$;e

$\sigma^{2} R_{W n_{D+k}}$ é a volatilidade segundo o modelo escolhido como benchmark - random walk - para a $D+k(k=[1,2])$, em relação à observação $n$.

Foram ainda efetuados dois testes adicionais: a verificação de viés de predição, e presença de previsões de volatilidades negativas por parte dos modelos. 0 viés de predição foi verificado obtendo-se, para cada model 0 , o percentual de vezes que a volatilidade prevista foi superior à volatilidade real. 0 teste de volatilidades negativas foi necessário uma vez que os testes de desempenho utilizados não capturam esta anomalia, o que poderia ocorrer nos modelos GARCH e TARCH.

Finalmente, procurou-se comparar os valores apontados pelos índices econométricos $\left(\mathrm{I}_{\text {eco }}\right)$ com os valores estipulados para o índice da taxa de câmbio contratual mente garantido $\left(I_{\text {est }}\right)$, estipulado pela Câmara. Os I eco (avaliação objetiva) são calculados segundo a abordagem paramétrica sugerida por Jorion, e adotada pela Câmara, para a determinação do valor em risco com um nível de confiança de $99 \%$, considerandose a volatilidade prevista por um modelo. Assim, foram calculados os val ores dos eco $_{\text {, }}$ tanto para $D+1$ quanto para $D+2$, utilizando-se os valores previstos para a volatilidade por cada um dos modelos estudados. Os valores estipulados $\left(\mathrm{I}_{\text {est }}\right)$ foram obtidos diretamente junto à Câmara, sendo definidos pelo seu Comitêapós uma análise concomitante do índice econométrico calculado e da conjuntura macroeconômica (avaliação subjetiva). De posse dos referidos valores, procedeuse a uma avaliação do comportamento dos índices durante o período da amostra, cujos resultados serão discutidos na próxima seção.

\section{ANÁLISE DOS RESULTADOS}

A Tabela 1 apresenta os resultados da primeira fase da investigação empírica, na qual se procurou observar as principais características estatísticas da série de retornos da taxa de câmbio. Para tanto, foram calculadas as estatísticas descritivas e efetuados testes ARCHLM para os três subperíodos anteriormente definidos e para o conjunto de observações da amostra.

A análise da estatística Jarque-Bera demonstra que, excetuando-se o subperíodo de 2 de janeiro de 2003 a 30 de setembro de 2003, no qual a economia brasileira esteve sob um rigoroso processo de ajuste monetário e fiscal, a hipótese de normalidade dos retornos é fortemente rejeitada. Mesmo no referido subperíodo, a assimetria positiva (indicando uma cauda direita longa) e a diferença entre a média e a mediana sugerem a rejeição da hipótese de normalidade, ainda que ao nível de significância de $34,48 \%$. A demais, pelos valores de curtose apresentados, a função densidade de probabilidade da série é sempre leptocúrtica.

Tabela 1 - Estatísticas descritivas e testes ARCH-LM para a série de retornos da taxa de câmbio.

\begin{tabular}{|l|c|c|c|c|}
\hline & $\begin{array}{c}21 / 08 / 2001 \\
\text { a } 30 / 09 / 2003\end{array}$ & $\begin{array}{c}21 / 08 / 2001 \\
\text { a } 19 / 04 / 2002\end{array}$ & $\begin{array}{c}22 / 04 / 2002 \\
\text { a } 30 / 12 / 2002\end{array}$ & $\begin{array}{c}02 / 01 / 2003 \\
\text { a } 30 / 09 / 2003\end{array}$ \\
\hline Número de observações & 535 & 170 & 177 & 188 \\
\hline Média & 0,025811 & 0,045752 & 0,236183 & $-0,107542$ \\
\hline Mediana & 0,037951 & 0,018709 & 0,276148 & $-0,071683$ \\
\hline Desvio padrão & 1,451340 & 1,001035 & 2,014266 & 1,107426 \\
\hline Assimetria & $-0,377459$ & $-0,462654$ & $-0,623717$ & 0,132103 \\
\hline Curtose & 8,667355 & 4,516232 & 6,698982 & 3,449513 \\
\hline Máximo & 5,260739 & 2,368977 & 5,260739 & 3,686976 \\
\hline Mínimo & $-10,34356$ & $-4,144737$ & $-10,34356$ & $-3,009965$ \\
\hline Jarque-Bera & 728,6881 & 22,34901 & 112,3844 & 2,129619 \\
\hline p-value & 0,000000 & 0,000014 & 0,000000 & 0,344794 \\
\hline ARCH-LM & 102,5001 & 6,879462 & 24,45136 & 12,88475 \\
\hline p-value & 0,000000 & 0,229760 & 0,000178 & 0,024483 \\
\hline
\end{tabular}


Percebe-se, também, que o período de maior instabilidade é aquel e que antecede as el eições majoritárias brasileiras de 2002 e se estende até a posse do novo governo (período de 22 de abril de 2002 a 30 de dezembro de 2002). Nesse período, observa-se o maior desvio padrão e os valores extremos (máximo e mínimo) de toda a amostra. A razão desse comportamento pode ser atribuída às incertezas econômicas e políticas vivenciadas em virtude da troca de comando no governo e a ascensão, pela primeira vez, de um partido de oposição à presidência da República até então no poder.

Em relação à heteroscedasticidade da série, os pvalues observados nas estatísticas ARCH-LM indicam uma forte presença de autocorrelação dos resíduos quadráticos no conjunto completo da amostra e em dois dos subperíodos. Apenas no subperíodo que antecede a entrada em operação da Câmara ( 21 de agosto de 2001 a 19 de abril de 2002) é que a hipótese de heteroscedasticidade teria que ser aceita em um nível de significância um pouco menor, ainda que representativo (grau máximo de certeza de 77,02\%). Dessa forma, os testes sugerem a rejeição da hipótese de homoscedasticidade na série de retornos da taxa de câmbio no contexto deste trabal ho.

Além disso, a partir da inspeção visual da Figura 1, que expressa o comportamento dos retornos diários da taxa de câmbio para todo o período da amostra, pode-se perceber que a série temporal demonstra, ainda, a presença de "clusters de volatilidade" e de um certo grau de assimetria na intensidade das respostas a eventos positivos e negativos. Verifica-se, portanto, que as características estatísticas da série de retornos da taxa de câmbio avalizam plenamente a utilização de modelos de volatilidade condicionada como os da classe ARCH.

Os resultados do desempenho preditivo dos diversos modelos estudados podem ser observados na Tabela 2. U ma primeira análise dessa tabela revela a superioridade dos modelos da família $A R C H$ em relação ao modelo EWMA. Apenas o modelo GARCH $(1,1)$, quando utilizado de forma restrita (ou seja, com a parametrização sugerida para o modelo EW MA pelo $M$ anual do RiskM etrics ${ }^{\mathrm{TM}}$ - janela móvel com 149 observações), apresenta uma capacidade preditiva inferior em todos os critérios. Além da restrição imposta, uma possível hipótese para o fraco desempenho do model o GARCH é a assimetria dos retornos, a qual não é capturada pelo modelo.

Corrobora essa hipótese a supremacia dos modelos assimétricos (EGARCH e TARCH), segundo todos os critérios e implementações, restritas ou não. Observase que para $D+1$, todos os critérios apontam o modelo $\operatorname{TARCH}(1,1)$ como o de melhor desempenho preditivo. Já para $D+2$, pode-se considerar que há um "empate técnico" entre os modelos TARCH $(1,1)$ e EGARCH $(1,1)$. Segundo o erro absoluto médio (EAM), o meIhor desempenho é do model o EGARCH. Por sua vez, segundo a raiz do erro quadrático médio (REQM), o melhor desempenho é do modelo TARCH. Finalmente, tomando-se por base a estatística Theil-U, a diferença de desempenho não é suficientemente represen-

Figura 1 - Retornos diários da taxa de câmbio para o período de 20/ 08/2001 a 30/09/2003.

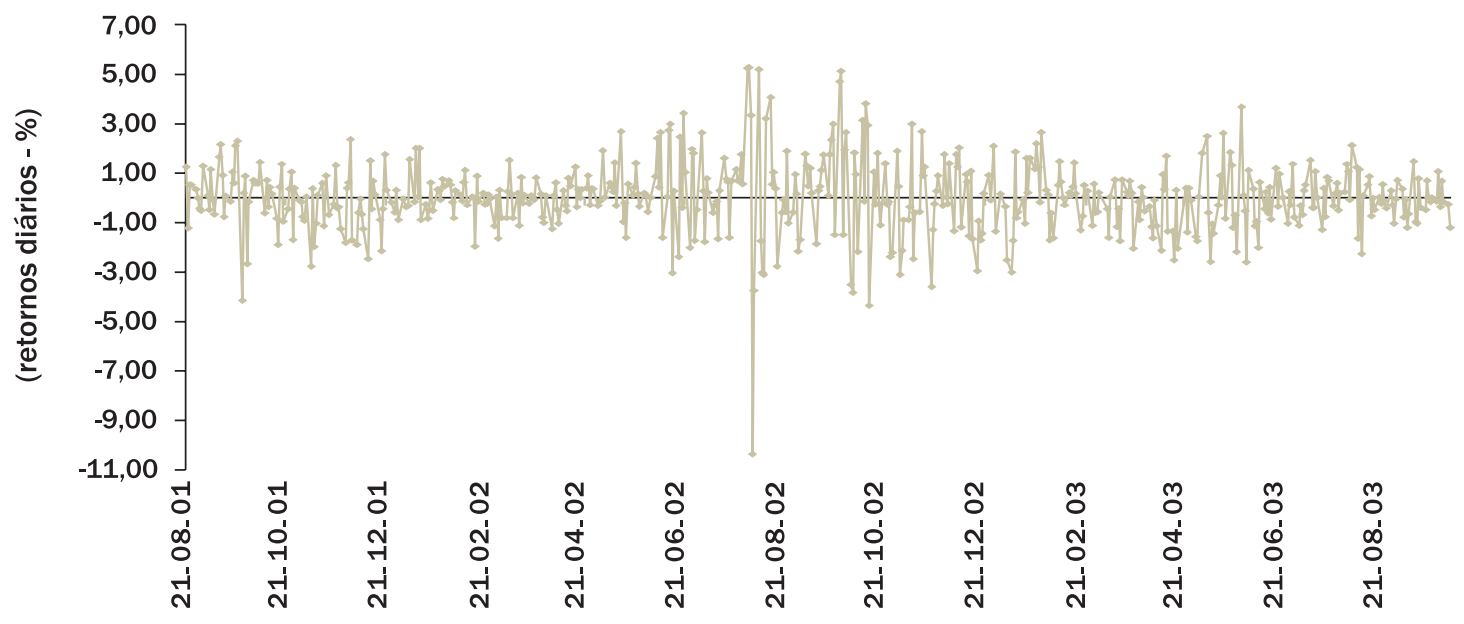


tativa para que se possa concluir pela superioridade de um modelo sobre o outro.

É importante observar que a estatística Theil-U proporciona, adicionalmente, uma comparação entre os modelos pesquisados e o modelo escolhido como benchmark, nesse caso, o Random Walk (RW). Por construção, o valor da estatística tem o seu limite inferior igual a zero - caso em que o modelo em teste apresenta todas as predições corretas -, sendo sempre igual a 1 para o modelo escolhido como benchmark. Dessa forma, pode-se verificar que todos os demais modelos apresentam um desempenho superior ao modelo RW, uma vez que as respectivas estatísticas Theil-U são sempre menores que a unidade. Entretanto, deve-se destacar que a diferença de desempenho para $D+2$ decresce substancialmente em comparação aos resultados observados para $D+1$.

A Tabela 2 permite ainda uma análise específica em relação aos três modelos da classe ARCH. Comparando-se o desempenho preditivo quando se emprega um número restrito de observações (149 neste caso) e quando são utilizadas todas as informações anteriormente disponíveis, verifica-se que todos os modelos se beneficiam com o aumento do número de observações utilizadas para a determinação de seus estimadores. Assim, as evidências empíricas apontam para a impropriedade de implementar restrições ao número de observações para o caso em que se optar pela utilização dos referidos modelos.

Conforme discutido anteriormente, devido ao fato de todos os critérios utilizados de avaliação de desempenho serem simétricos, fazem-se necessárias duas verificações adicionais - em relação às predições de volatilidade ponto a ponto - de forma a melhor validar os resultados obtidos: a ocorrência de volatilidades negativas e a presença de viés de estimação. No que tange à presença de volatilidades negativas, testou-se a presença de ocorrências da espécie nas predições efetuadas pelos modelos GARCH eTARCH, que, dentre os model os concorrentes, eram os únicos suscetíveis a esse tipo de erro. Como não foi constatada nenhuma falha nesse sentido, não há sob esse aspecto nenhuma objeção em relação aos resultados obtidos pelos critérios de avaliação.

Em relação à presença de viés de predição, todos os modelos revelaram uma tendência a superestimar a volatilidade futura. Como os valores observados não apresentaram diferenças significativas entre os modelos, também sob esse aspecto não se podem oferecer objeções em relação aos resultados obtidos pelos critérios de avaliação.

Em resumo, os resultados até aqui evidenciados indicam que todos os modelos pesquisados tendem a superestimar a volatilidade futura, sendo que os da família ARCH apresentam, no contexto desta pesquisa, um desempenho preditivo superior ao do modelo EWMA. Ademais, analisando-se em conjunto os resultados para $D+1$ e $D+2$, conclui-se também pela superioridade dos modelos assimétricos - em especial do modelo TARCH $(1,1)$ - na tarefa de predizer a volatilidade dos retornos da taxa de câmbio.

No que se refere à aplicação, no contexto da Clearing de Câmbio da BM\&F, das volatilidades previstas, a comparação do comportamento diário entre os índi-

Tabela 2 - Avaliação do desempenho dos modelos de predição da volatilidade.

\begin{tabular}{|c|c|c|c|c|c|c|}
\hline & \multicolumn{2}{|c|}{ EAM } & \multicolumn{2}{|c|}{ REQM } & \multicolumn{2}{|c|}{ THEIL-U } \\
\hline & $D+1$ & $\mathrm{D}+2$ & $D+1$ & $\mathrm{D}+2$ & $D+1$ & $D+2$ \\
\hline EWMA & $2,55260^{6}$ & $2,60278^{6}$ & $6,58520^{6}$ & $6,66287^{6}$ & $0,65176^{6}$ & $0,77933^{6}$ \\
\hline $\operatorname{GARCH}(1,1)^{\mathrm{R}}$ & $2,62931^{7}$ & $2,73502^{7}$ & $6,80383^{7}$ & $6,95599^{7}$ & $0,69576^{7}$ & $0,84940^{7}$ \\
\hline $\operatorname{EGARCH}(1,1)^{\mathrm{R}}$ & $2,48910^{5}$ & $2,46216^{4}$ & $6,39852^{3}$ & $6,42080^{3}$ & $0,61533^{3}$ & $0,72373^{3}$ \\
\hline $\operatorname{TARCH}(1,1)^{\mathrm{R}}$ & $2,43334^{3}$ & $2,45451^{3}$ & $6,45961^{5}$ & $6,57012^{5}$ & $0,62714^{5}$ & $0,75778^{5}$ \\
\hline $\operatorname{GARCH}(1,1)$ & $2,46712^{4}$ & $2,50530^{5}$ & $6,42875^{4}$ & $6,47017^{4}$ & $0,62116^{4}$ & $0,73490^{4}$ \\
\hline $\operatorname{EGARCH}(1,1)$ & $2,37078^{2}$ & $2,35160^{1}$ & $6,31596^{2}$ & $6,37893^{2}$ & $0,59956^{2}$ & $0,71432^{1}$ \\
\hline $\operatorname{TARCH}(1,1)$ & $2,35398^{1}$ & $2,35752^{2}$ & $6,08069^{1}$ & $6,14758^{1}$ & $0,55572^{1}$ & $0,71825^{2}$ \\
\hline
\end{tabular}

(a) 0 subscrito "R" indica que o modelo foi calculado de forma "restrita", ou seja, seguindo o mesmo procedimento aplicado ao modelo EWMA (janela móvel com 149 observações).

(b) Recordando, definiu-se como benchmark para a estatística Theil-U o modelo "Random Walk".

(c) Os subscritos numéricos nos valores das estatísticas indicam a ordem de classificação do modelo por coluna, sendo atribuído 0 valor 1 para 0 melhor desempenho e 7 para o pior. 
ces de taxa de câmbio contratualmente garantidos estipulados pela Câmara $\left(I_{\text {est }}\right)$ e os índices calculados com base no modelo de valor em risco $\left(I_{\text {eco }}\right)$ permitiu a identificação de três fases distintas, independentemente do model o analisado: o subperíodo compreendido entre 22 de abril de 2002 e 26 de juIho de 2002, representando o início das atividades da Câmara; o subperíodo compreendido entre 29 de julho de 2002 e 22 de outubro de 2002, que concentra os maiores valores calculados para o $\mathrm{I}_{\text {eco; }}$; 0 subperíodo compreendido entre 23 de outubro de 2002 a 26 de setembro de 2003, correspondendo ao final da amostra.

$\mathrm{Na}$ primeira fase, para todos os modelos, nota-se certo equilíbrio entre as avaliações subjetivas e objetivas na determinação do índice final. Percebe-se uma tendência, tanto para $D+1$ quanto para $D+2$, que as elevações no índice econométrico sejam acompanhadas por el evações no índice estipulado pela Câmara. Em relação aos impactos esperados caso a Câmara optasse pela substituição do modelo EW M A, verificase que para $D+1$ os valores calculados para $I_{\text {eco }}$ pelos demais modelos não ensejariam mudanças no ${ }_{\text {est' }}$ Já para $\mathrm{D}+2$, os modelos da família ARCH apontam para uma el evação no val or do I est' $^{\prime}$

A segunda fase apresenta a maior dissonância entre as avaliações objetivas e subjetivas. Logo no início, enquanto todos os modelos econométricos sinalizam para um aumento substancial nos valores do est' a avaliação subjetiva parece considerar tal aumento por demais exagerado. Assim, verifica-se, principalmente para $D+2$, que os val ores estipulados ficam aquém, em maior ou menor grau, dependendo do modelo, dos valores indicados pela aval iação objetiva. No que tange aos impactos esperados em razão da substituição de modelos, os da família ARCH apontam, com mais intensidade que o model o EW M A, para a necessidade de el evação do valor $I_{\text {est' }}$ o que, de al guma forma, poderia sensibilizar o Comitê da Câmara.

A última fase é marcada pelo predomínio crescente da avaliação subjetiva em rel ação à avaliação objetiva, na medida em que se aproxima do final da amostra. Enquanto todos os modelos econométricos apresentam uma ten dência decrescente para os valores do $I_{\text {eco' }}$ 0 valor do I se mantém constante, seja para $D+1$ ou $D+2$. N essa fase, dada a diferença entre os valores calculados para o I eco e os valores definidos pela Câmara, não há razão para se supor que uma mudança no modelo econométrico utilizado pudesse causar algum impacto no I est. .

Com base nas análises anteriores e considerando que 0 índice econométrico é calculado segundo procedimentos estatísticos que, em princípio, predizem a variação da taxa de câmbio em um nível de confiança de $99 \%$, a tendência observada de distanciamento progressivo entre o índice de variação da taxa de câmbio estipulado pela Câmara e o apontado pelo método econométrico sugere um excesso de conservadorismo ou um relativo descrédito nos procedimentos estatísticos adotados. Nota-se, também, que no período de maior volatilidade, a avaliação subjetiva subestimou, por vezes, a volatilidade real, contrariando as indica-

Figura 2 - Comparação entre volatilidade real, $\mathrm{I}_{\text {eco }}$ e $\mathrm{e}_{\text {est }}$ no período da amostra.

(a) $I_{\text {eco }}$ calculado utilizando o modelo EWMA para $D+1$

(\%)

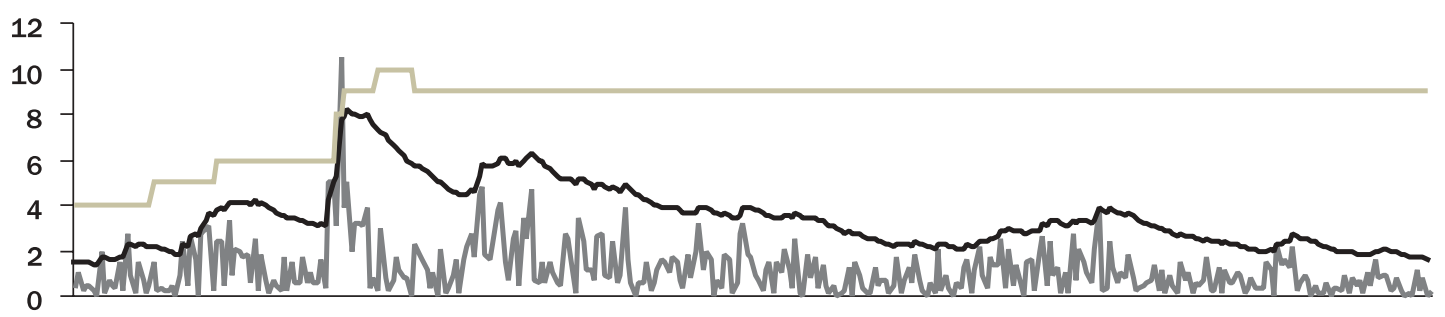

\begin{tabular}{|c|c|c|c|c|c|c|c|c|c|c|c|c|c|c|c|c|c|}
\hline$N$ & N & $N$ & N & N & N & N & N & N & $m$ & $m$ & $m$ & $m$ & $m$ & $m$ & $m$ & $m$ & $m$ \\
\hline 0 & 0 & 0 & 0 & 0 & 0 & 0 & 0 & 0 & 0 & 0 & 0 & 0 & 0 & 0 & 0 & 0 & 0 \\
\hline ナ & 1) & 0 & $N^{\prime}$ & $\infty^{\prime}$ & a' & $0^{\prime}$ & 'ं & ' & त' & N' & m' & 寸 & 'م' & 0 & $N$ & $\infty^{\prime}$ & a \\
\hline 0 & 0 & 0 & 0 & 0 & 0 & $\lambda$ & $r$ & r & 0 & 0 & 0 & 0 & 0 & 0 & 0 & 0 & 0 \\
\hline$N$ & N่ & - & N' & $0^{\prime}$ & $\infty^{\prime}$ & $N^{\prime}$ & $\infty^{\prime}$ & $N^{\prime}$ & $0^{\prime}$ & $\infty^{\prime}$ & 'ं & m' & m' & 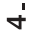 & m' & 'ં & の \\
\hline$N$ & $N$ & $N$ & $N$ & $N$ & त & $r$ & त & त & $N$ & $r$ & $N$ & $N$ & $N$ & $N$ & N & $N$ & -1 \\
\hline
\end{tabular}


(b) I eco calculado utilizando o modelo EWMA para D+2

(\%)

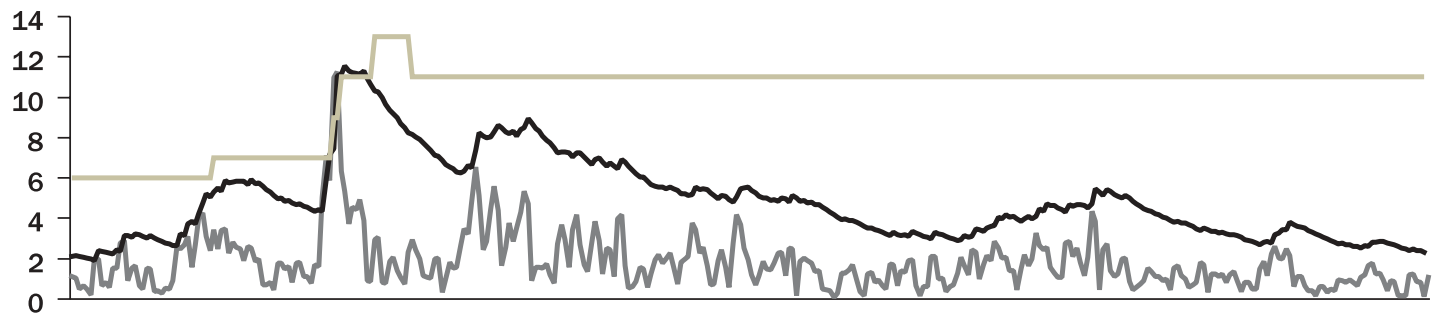

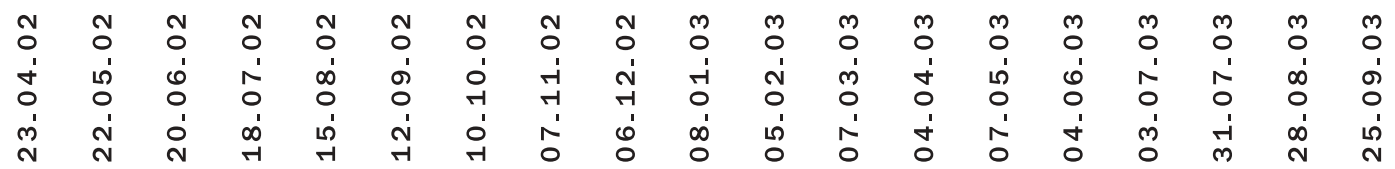

Vol real Acm. 2 dias

leco EWMA

lest

(c) I eco calculado utilizando o modelo $\operatorname{GARCH}(1,1)$ para D+1

(\%)

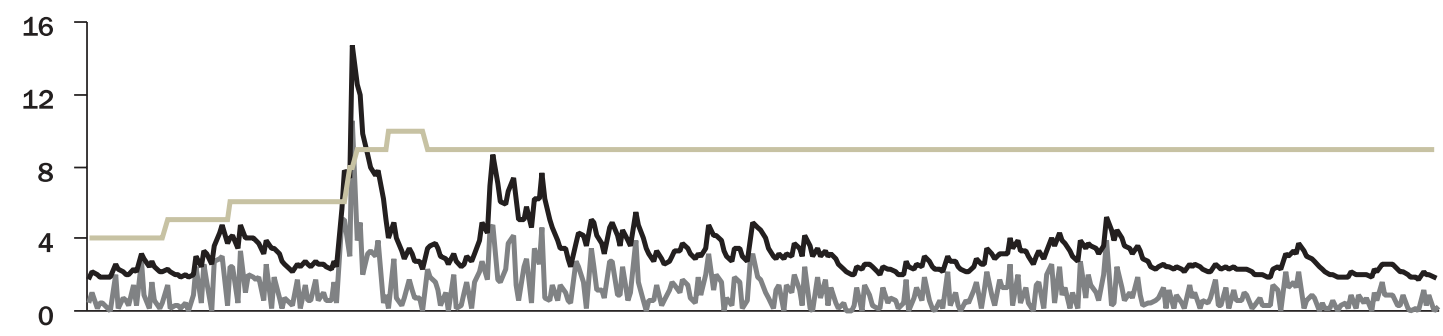

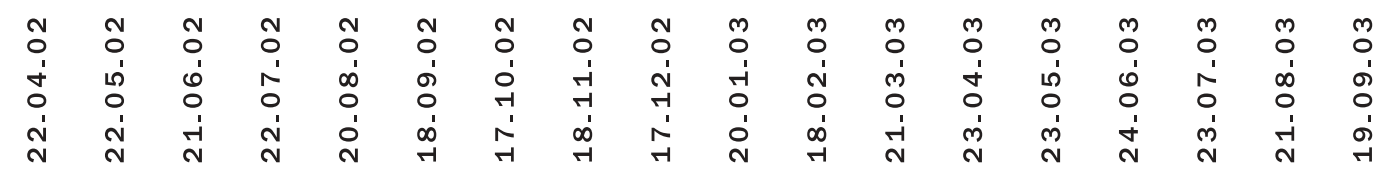

Vol real

leco GARCH

lest

(d) $I_{\text {eco }}$ calculado utilizando o modelo $\operatorname{GARCH}(1,1)$ para $D+2$

(\%)

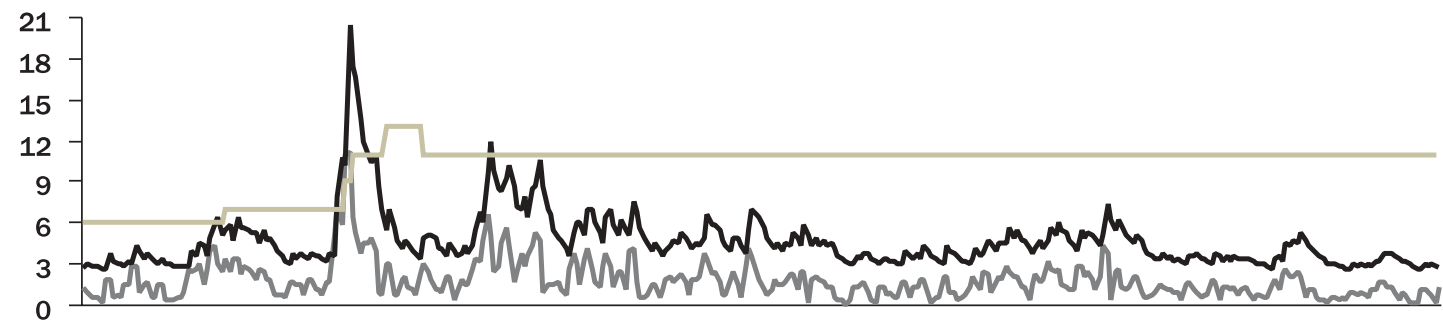

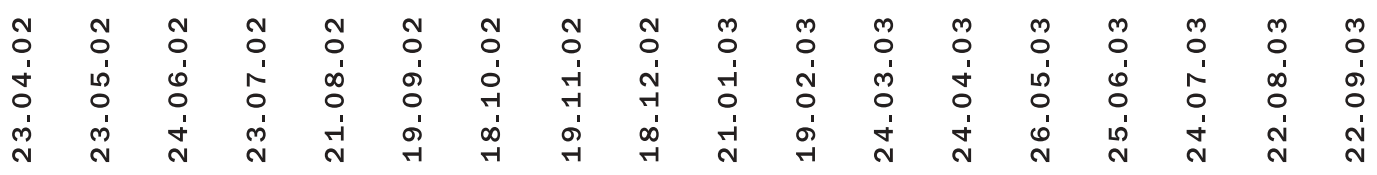

Vol real Acm. 2 dias

leco GARCH lest 
(e) $I_{\text {eco }}$ calculado utilizando o modelo $\operatorname{EGARCH}(1,1)$ para $D+1$

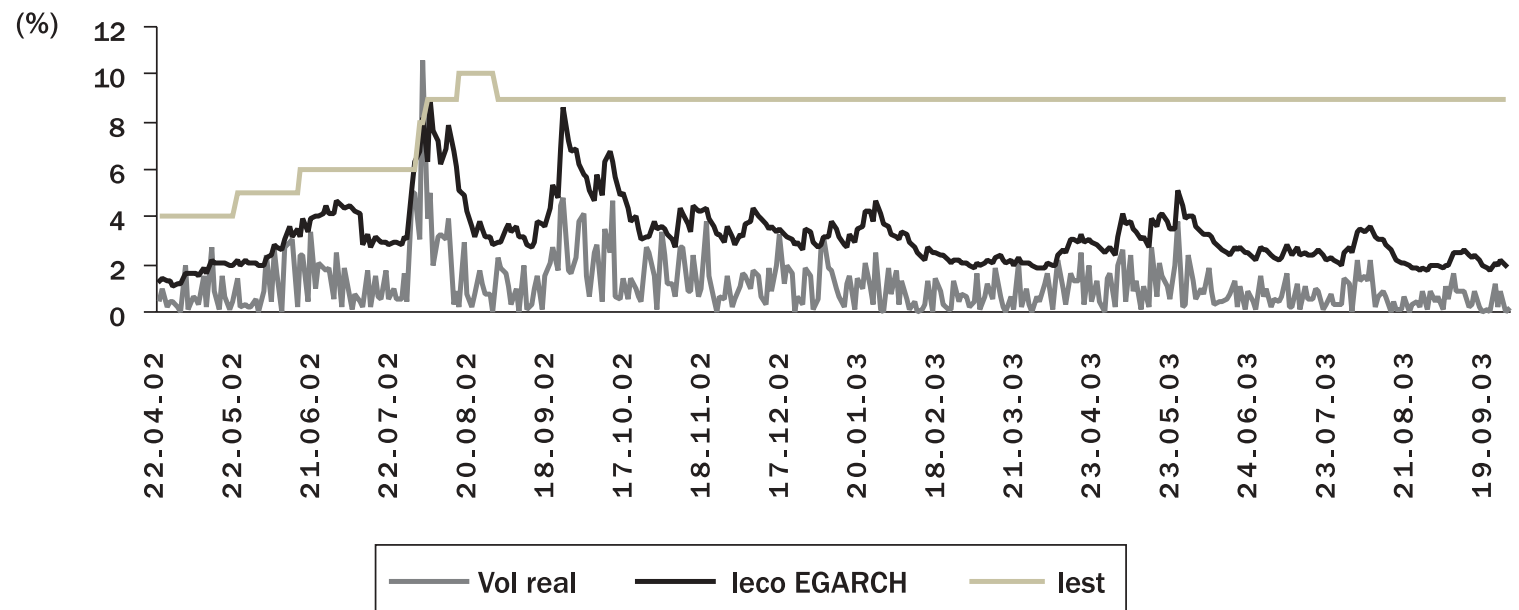

(f) ecc $_{\text {ec }}$ calculado utilizando o modelo $\operatorname{EGARCH}(1,1)$ para $D+2$

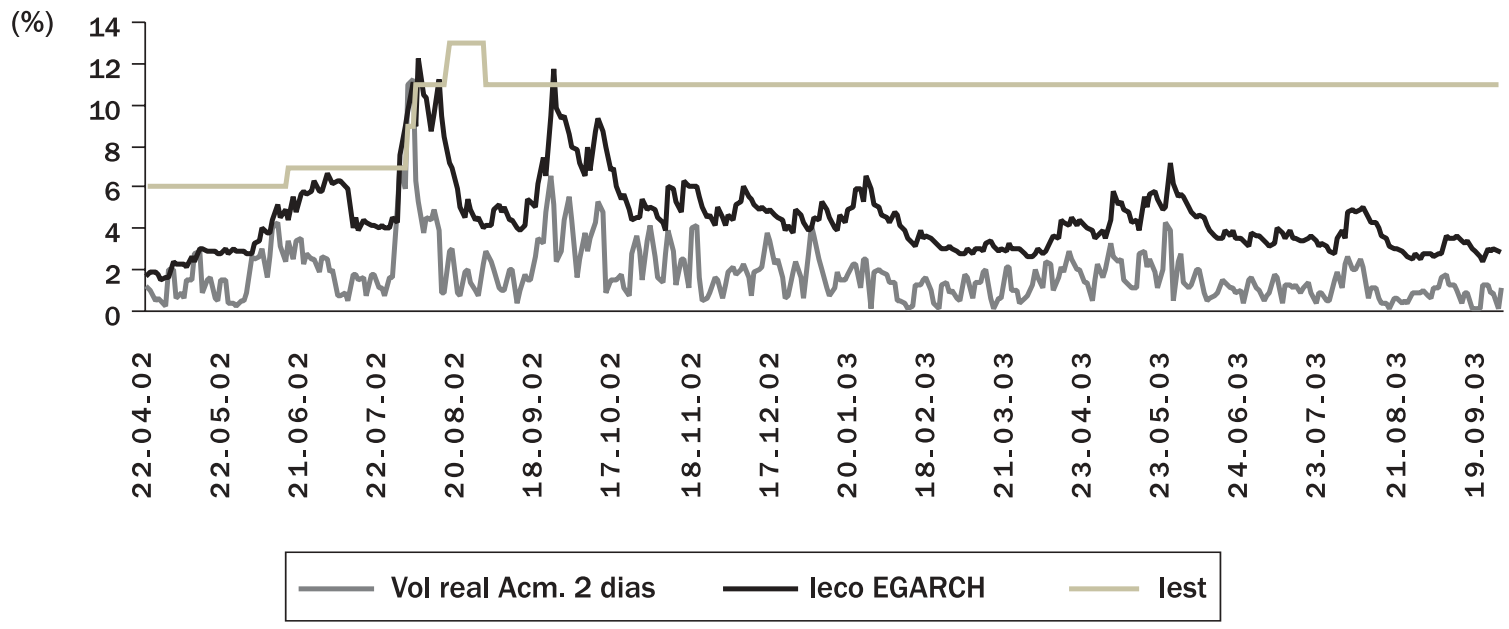

(g) I eco calculado utilizando o modelo $\operatorname{TARCH}(1,1)$ para $\mathrm{D}+1$

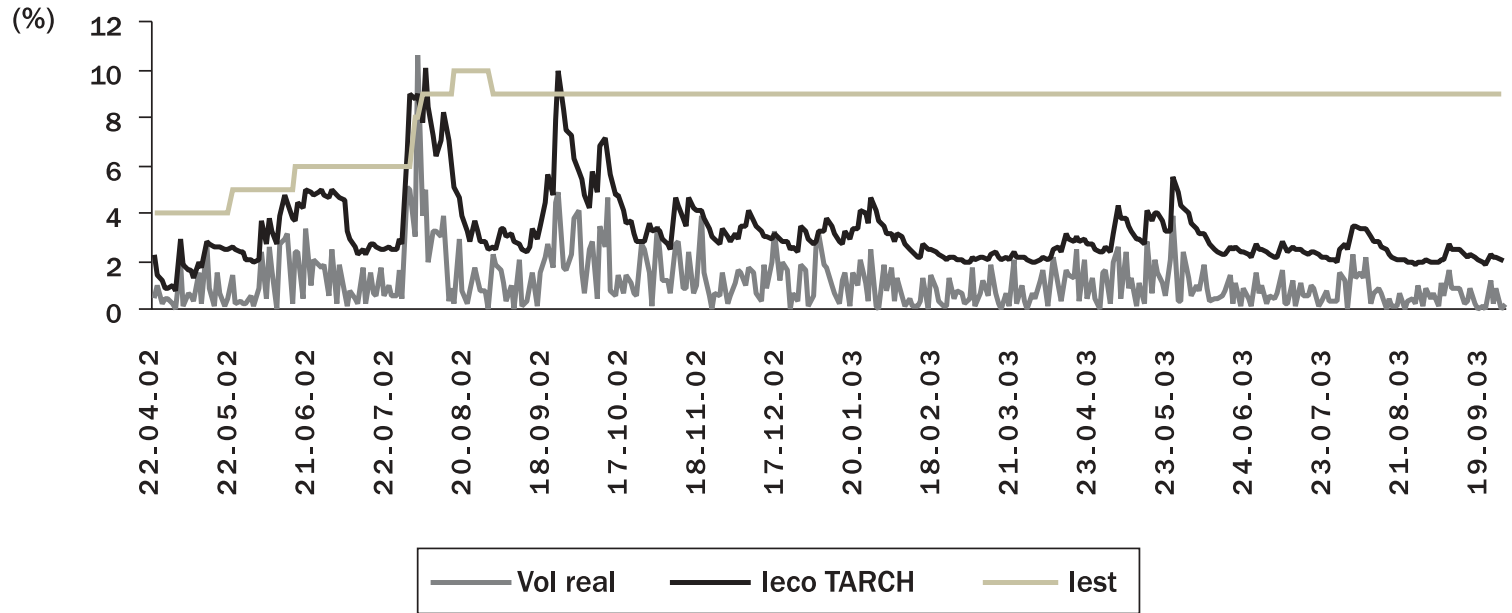


(h) $I_{\text {eco }}$ calculado utilizando o modelo $\operatorname{TARCH}(1,1)$ para $D+2$

(\%)

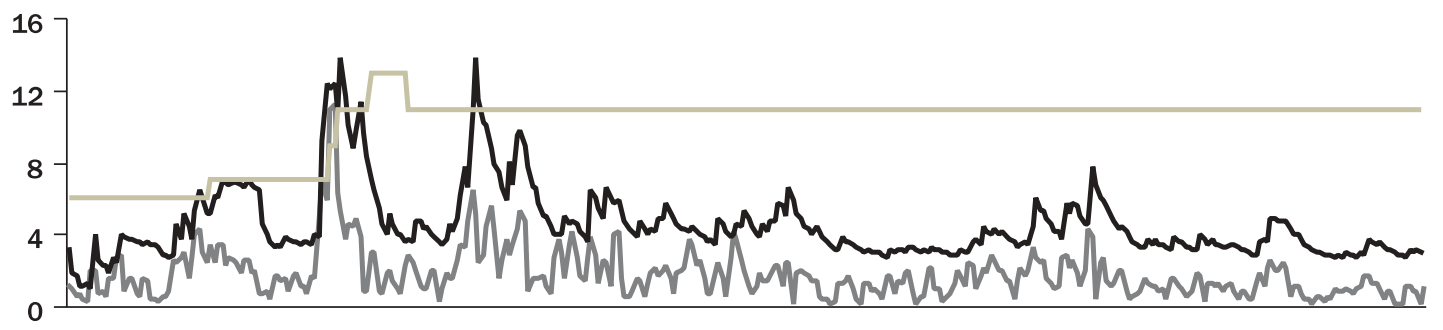

\begin{tabular}{|c|c|c|c|c|c|c|c|c|c|c|c|c|c|c|c|c|c|}
\hline$N$ & $N$ & $N$ & $N$ & N & $N$ & N & $N$ & N & $m$ & $m$ & $m$ & $m$ & $m$ & $m$ & $m$ & $m$ & $m$ \\
\hline 0 & 0 & 0 & 0 & 0 & 0 & 0 & 0 & 0 & 0 & 0 & 0 & 0 & 0 & 0 & 0 & 0 & 0 \\
\hline$\dot{\theta}$ & م) & 0 & $N$ & $\infty^{\prime}$ & a' & $0^{1}$ & 'ं & ' & त' & $N$ & $m$ & $\nabla$ & ) & 0 & $N$ & $\infty$ & $\sigma$ \\
\hline 0 & 0 & 0 & 0 & 0 & 0 & $\lambda$ & H & $\lambda$ & 0 & 0 & 0 & 0 & 0 & 0 & 0 & 0 & 0 \\
\hline$m$ & m' & 'ं & $m$ & तi & ब' & $\infty$ & の & $\infty$ & त & の & 8 & 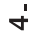 & 0 & 10 & $\forall$ & N & N \\
\hline$N$ & $N$ & $N$ & $N$ & $N$ & 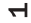 & $r$ & $r$ & $r$ & $N$ & $r$ & $\mathbf{N}$ & $N$ & $N$ & $\mathbf{N}$ & $N$ & $N$ & $N$ \\
\hline
\end{tabular}

\begin{tabular}{|lll|}
\hline Vol real Acm. 2 dias $\quad$ leco TARCH $\quad$ lest \\
\hline
\end{tabular}

ções dos modelos econométricos. Dessa forma, podese concluir que, mantida essa tendência, nenhum efeito prático deve ser esperado de uma eventual substituição do modelo EWMA por qualquer dos modelos concorrentes. A Figura 2 apresenta os gráficos comparativos entre a volatilidade real, $\mathrm{I}_{\text {est }}$ e ${ }_{\text {eco' }}$, para $D+1$ e $D+2$, segundo cada um dos modelos estudados.

\section{CONCLUSÕES}

No contexto desta pesquisa, conclui-se que o modelo $\operatorname{TARCH}(1,1)$ é o que apresenta melhor desempenho preditivo, sendo acompanhado de perto pelo modelo EGARCH $(1,1)$. Em seguida, tem-se o modelo GARCH $(1,1)$ e, por último, o modelo EW MA, ressal tando-se que todos os modelos apresentam uma tendência a superestimar a volatilidade futura. Conclui-se, ainda, pela inadequação, nos modelos da classe ARCH, de implementar restrições em relação ao número de observações utilizadas no processo de estimação dos parâmetros da equação da volatilidade condicional, haja vista a queda acentuada no desempenho preditivo, em especial do modelo GARCH. Ademais, verificouse que o modelo Random Walk não deve ser considerado como uma alternativa viável aos modelos econométricos utilizados neste estudo, uma vez que, conforme demonstrado pela estatística Theil-U, estes últimos apresentam um desempenho significativamente superior.
Os resultados acima confirmam o fato, preconizado pela teoria, de que a abordagem econométrica representada pelos modelos da classe ARCH é a mais adequada para o tratamento de séries que apresentam heteroscedasticidade, agrupamentos de volatilidade e leptocurtose, características verificadas na série de retornos das taxas de câmbio utilizada neste trabalho. Constatou-se também a característica de reação assimétrica a boas e más notícias, o que guarda relação direta com o melhor desempen ho preditivo observado para os modelos TARCH eEGARCH, de resposta assimétrica, comparativamente aos modelos GARCH e EWMA, de resposta simétrica.

Em relação ao contexto operacional da Clearing, verificou-se um excesso de garantias em boa parte da amostra, sendo que, no período de maior volatilidade, a aval iação subjetiva adotada pela Câmara subestimou, por vezes, a volatilidade real, contrariando as indicações dos model os econométricos. Essa supremacia da avaliação subjetiva sobre a objetiva pode estar fundamentada em um relativo descrédito nos procedimentos estatísticos ora adotados pela Câmara. N esse caso, à semelhança do ocorrido com a Clearing de Derivativos da $B M \& F$, sugere-se a reavaliação dos modelos utilizados de forma a minimizar o volume total de garantias exigidas sem comprometer a segurança do sistema.

Para finalizar, devem ser ressaltadas as limitações deste trabalho, como o restrito número de observações decorrente do curto prazo de operação da Câmara; a presença de pontos controversos e ainda 
inconclusos no meio acadêmico, inclusive a definição da volatilidade real e a determinação da medida de desempenho preditivo mais apropriada para modelos de volatilidade e o caráter probabilístico dos resultados. Dessa forma, os resultados aqui obtidos não têm a pretensão de sinal izar o fim das discussões acerca do melhor modelo de predição de volatilidade, mas sim recolocar em discussão um tema de crucial importância para o gerenciamento de riscos e a precificação de operações no mercado interbancário brasileiro. Nesse sentido, sugere-se a replicação do presente trabal ho, ampliando-se o intervalo da amostra e utilizando-se dados de alta freqüência, bem como o desenvolvimento de estudos visando caracterizar a tendência a superestimar a volatilidade dos modelos avaliados.

\section{NOTAS}

1 Eviews $^{T M}$ éum pacote estatístico desenvolvido pela empresa Q uantitative Micro Software, que proporciona um conjunto de funções predefinidas para suporte à análise econométrica de dados. Mais informações podem ser obtidas no site www.eviews.com.

\section{REFERÊNCIAS BIBLIOGRÁFICAS}

ALEXANDER, C. (Ed.). Risk Management and Analysis. v. 1: Measuring and Modeling Financial Risk. West Sussex: John Wiley, 1998.

ALEXANDER, C. Market Models: A Guide to Financial Data Analysis. West Sussex: John Wiley, 2002.

BERTUCCI, L. A. Avaliação de opções sob consideração de volatilidades históricas, implícitas e condicionadas - o caso Telebrás na Bovespa. 1999. 150 p. Tese (Doutorado em Administração) - Escola de Administração de Empresas de São Paulo: Fundação Getúlio Vargas. São Paulo.

BM \& F: Bolsa de Mercadorias \& Futuros. Câmara de Registro, Compensação e Liquidação de 0 perações de $C$ âmbio $B M \& F$ : regulamento, manual de operações, manual de gerenciamento de risco e órgãos auxiliares de administração. São Paulo: BM \& F, 2002.
BOLLERSLEV, T. Generalized autoregressive conditional heteroskedasticity. Journal of Econometrics, v. 31, p. 307-327, 1986.

BOLLERSLEV, T.; CHOU, R. Y.; KRONER, K. F. ARCH modeling in finance: a review of theory and empirical evidence. Journal of Econometrics, v. 52, p. 5-59, 1992.

BRO OKS, C. Introductory Econometrics for Finance. Cambridge, UK: Cambridge University Press, 2002.

DAY, T.; LEWIS, C. Stock market volatility and the information content of stock index options. Journal of Econometrics, v. 52, p. 267-287, 1992.

ENGLE, R. F. Autoregressive conditional heteroscedasticity with estimates of the variance of U nited Kingdom inflation. Econometrica, v. 50, n. 4 , p. $987-1007,1982$.

FAMA, E. The behavior of stock market prices. Journal of Business, n. 38, p. 34-105, 1965.

GLOSTEN, L. R.; JAGANATHAN, R.; RUN KLE, D. E. On the relation between the expected value and the volatility of the nominal excess returns on stocks. Journal of Finance, v. 48, p. 1779-1801, 1993.

GOURIÉROUX, C. Arch M odels and Financial Applications. N ew York: Springer-Verlag, 1997.

JORION, P. Value at risk: a nova fonte de referência para o controle do risco de mercado. São Paulo: Cultura, 1998.

MANDELBROT, B. The variation of certain speculative prices. Journal of Business, v. 36, p. 394-419, 1963.

MERTON, R. C. On estimating the expected return on market: an exploratory investigation. Journal of Financial Economics, v. 8, p. 323$361,1980$.

MARKOWITZ, H. Portfolio selection. Journal of Finance, v. 7, n. 1, p. 77-91, 1952.

MORGAN GUARANTY TRUST COMPANY \& REUTERS LTD. RiskM etrics: Technical Document. $4^{\text {th. }}$ ed., New York: RiskMetrics, 1996.

NELSON, D. B. Conditional heteroskedasticity in asset return: a new approach. Econometrica, v. 59, n. 2, p. 347-370, 1991.

PAGAN, A. R.; SCHWERT, G. W. Alternative models for conditional stock volatility. Journal of Econometrics, v. 45, p. 267-290, 1990.

POON, S.; GRANGER, C. W. J. Forecasting volatility in financial markets: a review. Journal of Economic Literature, v. 41, p. 478-539, 2003. 


\section{Artigo recebido em 23.08.2004. Aprovado em 18.07.2005.}

\section{Clayton Peixoto Goulart}

Pesquisador do NUFI/UFM G-CEPEAD, do CEGE/UFMG-CEPEAD e do IBMEC-MG. Mestre em Administração pela UFMG.

Interesses de pesquisa nas áreas de mercado financeiro, de capitais e de derivativos e métodos e modelos matemáticos, econométricos e estatísticos.

E-mail: clayton@cepead.face.ufmg.br

Endereço: Rua Francisco Bicalho, 2385, ap. 301, Caiçaras, Belo Horizonte - M G, 30720-340.

\section{Hudson Fernandes Amaral}

Professor da UFM G-CEPEAD. Doutor em Administração pela Université Pierre M endes - France. Interesses de pesquisa nas áreas de finanças corporativas, mercado financeiro, de capitais e de derivativos, finanças públicas.

E-mail: hfamaral@face.ufmg.br

Endereço: Rua Curitiba 832, 10 andar, Centro, Belo Horizonte - MG, 30170-120.

\section{Luiz Alberto Bertucci}

Professor da UFMG-CEPEAD. Doutor em Administração pela FGV-EAESP.

Interesses de pesquisa nas áreas de mercado financeiro, de capitais e de derivativos, finanças corporativas, estratégia.

E-mail: bertucci@face.ufmg.br

Endereço: Rua Curitiba 832, 10 andar, Centro, Belo Horizonte - MG, 30170-120.

\section{Aureliano Angel Bressan}

Professor da UFMG-CEPEAD. Doutor em Economia A plicada pela UFV.

Interesses de pesquisa nas áreas de técnicas de avaliação de investimentos em renda variável, análise de séries temporais em finanças, métodos e modelos matemáticos, econométricos e estatísticos.

E-mail: bressan@face.ufmg.br

Endereço: Rua Curitiba 832, 10 andar, Centro, Belo Horizonte - MG, 30170-120. 